\title{
Heart and soul
}

\author{
Alden H. Harken, MD, FACS
}

See related article on pages 2373-9.

As cardiac surgeons, our primary goal is to make certain that the body of our patient remains connected to his or her soul. In their article in this issue of the Journal, Paparella and colleagues ${ }^{1}$ propose the not-too-surprising hypothesis that increasing perioperative cardiomyocyte damage increases the likelihood of our patient's soul departing his or her body. The image of a completely innocuous myocardial preservation strategy has, like a mirage, haunted cardiac surgeons for decades.

Paparella and colleagues ${ }^{1}$ serially measured cardiac troponin I (cTnI) in 965 patients after mitral and aortic valve surgery. They found higher cTnI after mitral valve surgery than after aortic valve surgery, and they concluded that inclusion of postoperative $\mathrm{cTnI}$ in a reference model that permitted stratification for New York Heart Association functional class, left ventricular ejection fraction, and duration of cardiopulmonary bypass improved the model's statistical relationship with postoperative morbidity and mortality at 3 months. Paparella and colleagues ${ }^{1}$ refer to this increased cTnI as a "risk" and postulate that during myocardial revascularization procedures (such as coronary artery bypass grafting), "coronary disease extension, recent myocardial infarction, and incomplete revascularization" may lead to myocardial damage, whereas in valve surgery, the efficacy of cardioplegia is just as likely to be related to cellular necrosis. If indeed cTnI is elaborated when cardiomyocytes succumb and spill out this intracellular enzyme, then all cardiac surgery provokes at least some bump in cTnI when oxygen and substrate delivery does not meet oxygen and substrate demand. For aortic valve surgery, there is extraordinarily limited direct incisional damage to the myocardium; in mitral valve surgery, the atrial incision is unlikely to release much cTnI. A hypertrophic left ventricle as a result of aortic stenosis may predispose toward myocardial

\footnotetext{
From the Department of Surgery, University of California, San Francisco-East Bay, Oakland, Calif.

Disclosures: Author has nothing to disclose with regard to commercial support.

Received for publication Sept 8, 2014; accepted for publication Sept 9, 2014.

Address for reprints: Alden H. Harken, MD, FACS, Department of Surgery, University of California, San Francisco-East Bay, 1411 E 31st St, QIC 22134, Oakland, CA 94602 (E-mail: alden.harken@ucsfmedctr.org).

J Thorac Cardiovasc Surg 2014;148:2380

0022-5223/ $\$ 36.00$

Copyright (c) 2014 Published by Elsevier Inc. on behalf of The American Association for Thoracic Surgery

http://dx.doi.org/10.1016/j.jtcvs.2014.09.010
}

ischemia, and a dilated left ventricle as a result of mitral insufficiency may also exacerbate the ventricular "tension," driving up oxygen demand by the rule of Laplace. Thus it seems that analysis of any increase in postoperative cTnI must always focus on the adequacy of cardioplegia delivery as an etiology.

Unfortunately, Paparella and colleagues ${ }^{1}$ were not able to detect an association between $\mathrm{cTnI}$ increase and the type $(P=.26)$, temperature $(P=.17)$, or mode of delivery $(P=.32)$ of the cardioplegic solution. Importantly, however, they do shine a bright light on the disappointing fact that we have not yet achieved "optimal" myocardial preservation practice-especially during mitral valve surgery.

To date, cardiac surgeons have focused on driving down myocardial oxygen and substrate use after the application of the crossclamp. The Fullerton laboratory in Colorado ${ }^{2,3}$ has identified an interleukin 1-nuclear factor $\kappa$ B-heat shock protein 27 inflammatory pathway that is provoked by crossclamp-induced ischemia and reperfusion. Cardiac surgeons should glory in the recognition that we already deserve a favorable grade for protecting cardiomyocytes during surgery. If we dream of truly aspiring to honors status, however, perhaps we should add an anti-inflammatory agent to our cardioplegic solution.

It would seem that a "risk" is avoidable only when you haven't taken it yet. Once cardiomyocytes are dead, and the cTnI is detected, the dead ones become a handicap, not a risk. The message of this important study ${ }^{1}$ therefore is that to prevent our patients' souls from crossing through the pearly gates, we must not just target oxygen and substrate imbalance in our myocardial preservation strategies but also, perhaps, add a "pinch" of anti-inflammatory sauce to our cardioplegic stew.

\section{References}

1. Paparella D, Guida P, Caparrotti S, Fanelli V, Martinelli G, Mazzei V, et al Myocardial damage influences short and mid-term survival after valve surgery: a prospective multicenter study. J Thorac Cardiovasc Surg. 2014; 148:2373-9.

2. Jin C, Cleveland JC, Ao L, Zeng Q, Fullerton DA, Meng X. Human myocardium releases heat shock protein 27 (HSP27) after global ischemia: the proinflammatory effect of extracellular HSP27 through toll-like receptor (TLR)-2 and TLR4. Mol Med. 2014;20:280-9.

3. Lee JK, Meng X, Weyant MJ, Reece TB, Cleveland JC Jr, Fullerton DA. Stenotic aortic valves have dysfunctional mechanisms of anti-inflammation: implications for aortic stenosis. J Thorac Cardiovasc Surg. 2011;141:481-6. 